Meta

Journal des traducteurs

Translators' Journal

\title{
The Effect of Ear of Information Reception on the Proficiency of Simultaneous Interpretation
}

\section{Sylvie Lambert}

Volume 38, numéro 2, juin 1993

URI : https://id.erudit.org/iderudit/003385ar

DOI : https://doi.org/10.7202/003385ar

Aller au sommaire du numéro

Éditeur(s)

Les Presses de l'Université de Montréal

ISSN

0026-0452 (imprimé)

1492-1421 (numérique)

Découvrir la revue

Citer cet article

Lambert, S. (1993). The Effect of Ear of Information Reception on the Proficiency of Simultaneous Interpretation. Meta, 38(2), 198-211. https://doi.org/10.7202/003385ar

\section{Résumé de l'article}

Cette étude établit un lien entre l'interprétation simultanée et la prédominance d'un hémisphère cérébral. Pour ce faire, elle compare la compétence relative des interprètes lorsque ceux-ci reçoivent l'information à traduire par une seule oreille d'une part, et par les deux d'autre part. Dix-huit sujets (interprètes professionnels et étudiants en interprétation) ont interprété simultanément de L2 à Ll trois passages oraux, ceux-ci étant perçus par chacune des oreilles, puis par les deux. Il ressort de l'expérience que la performance des interprètes s'améliore nettement lorsque le message leur parvient par une seule oreille. De plus, il y a lieu de croire que le transfert s'effectuant de l'oreille gauche à l'hémisphère droit a le mieux réussi. Les résultats sont évalués quant à la nature des tâches effectuées lors d'une interprétation simultanée, comme dans le cas de la prédominance d'un hémisphère cérébral chez les personnes bilingues. 


\title{
THE EFFECT OF EAR OF INFORMATION RECEPTION ON THE PROFICIENCY OF SIMULTANEOUS INTERPRETATION
}

\author{
SYLVIE LAMBERT \\ University of Ottawa, Ottawa, Canada
}

\begin{abstract}
Résumé
Cette étude établit un lien entre l'interprétation simultanée et la prédominance d'un hémisphère cérébral. Pour ce faire, elle compare la compétence relative des interprètes lorsque ceux-ci reçoivent l'information à traduire par une seule oreille d'une part, et par les deux d'autre part. Dix-huit sujets (interprètes professionnels et étudiants en interprétation) ont interprété simultanément de L2 à Ll trois passages oraux, ceux-ci étant perçus par chacune des oreilles, puis par les deux.

Il ressort de l'expérience que la performance des interprètes s'améliore nettement lorsque le message leur parvient par une seule oreille. De plus, il y a lieu de croire que le transfert s'effectuant de l'oreille gauche à l'hémisphère droit a le mieux réussi. Les résultats sont évalués quant à la nature des tâches effectuées lors d'une interprétation simultanée, comme dans le cas de la prédominance d' un hémisphère cérébral chez les personnes bilingues.
\end{abstract}

\begin{abstract}
In an attempt to bring together information about simultaneous interpretation, on the one hand, and cerebral dominance, on the other, this study examines the relative proficiency of interpreters when processing information received through one ear or the other as opposed to two ears. Eighteen subjects (professional interpreters and interpretation students) simultaneously interpreted spoken passages from L2 to L1: one passage was presented to the interpreters' left ear, one to their right ear, and one to both ears.

Results indicated that interpreters performed significantly better when the message was presented to one ear or the other rather than to both ears. Furthermore, there was evidence suggesting that the left-ear-to-right-hemisphere route yielded the best performance. The results are discussed in terms of the nature of the tasks involved during simultaneous interpretation as well as cerebral dominance among bilingual individuals.
\end{abstract}

Two general questions underly the present study: 1) Are the cognitive strategies of simultaneous interpreters more like those of bilinguals than those of monolinguals, and 2) should the source message that interpreters are required to process be relayed through both headphones stereophonically, or via one ear, be it left or right? The purpose of the study is to examine this division of cerebral labour among simultaneous or conference interpreters who perform a number of very demanding tasks in terms of the cognitive processes activated in the course of interpretation.

The idea for the present study originated from the observation that, from time to time, some professional interpreters slide one headphone slightly off one ear while interpreting. One wonders why interpreters might want to release one ear and whether or not the same ear is always released; does this habit depend on an interpreter's handedness or telephone habits; is language direction involved, i.e. does working from one's second or passive language (L2) into one's mother-tongue or active language (L1), or vice versa, play a role? 


\section{EVIDENCE FROM DICHOTIC LISTENING EXPERIMENTS}

Very early in the use of the "dichotic paradigm", using monolingual subjects, researchers demonstrated that the presentation of verbal material resulted in better information processing when the input was directed to the right ear than when directed to the left ear (Broadbent 1954). Later, this right ear advantage (REA), found in the dichotic presentation of verbal input, was ascribed to left hemisphere dominance for speech processing and the preeminence of the contralateral auditory connections between the right ear and the left hemisphere (Bartz, Satz, and Fennel 1967; Broadbent and Gregory 1964; Bryden 1967; Carr 1969; Kimura 1961a, 1961b; Satz 1968). The REA in verbal listening, with words or digits as input, has been reported as well with monaural stimulation, but the phenomenon seems to occur more consistently when competition takes place between the auditory pathways. The REA has been interpreted by some as resulting from ear differences in perceptual sensitivity (Kimura 1967; Satz 1968), although this seems to be a superficial assessment of the case (Satz, Levy, and Tyson 1970). Morais (1978) and Bertelson (1982) reported a right side advantage by using two simultaneously presented messages played through each of two loudspeakers on either side of the subject, so that both messages could reach either ear. In these experiments, loudspeakers were substituted for headphones in a hemispace analogue of dichotic listening, where hemispace, as distinct from ear, hand, or visual field, refers to corporeal space to the left or right of the body midline. Pierson, Bradshaw and Nettleton (1983) also obtained robust right-side advantages when competing verbal stimuli were presented simultaneously from a single, laterally placed loudspeaker.

In Geffen and Quinn's (1984) review, a question is raised as to whether speech is exclusively processed by the specialized hemisphere, or whether one hemisphere is relatively more specialized than the other. Kinsbourne (1975a, 1975b) proposed an attentional model to explain laterality effects, including the REA in dichotic listening. He argued that each cerebral hemisphere controls attention directed contralaterally. The two hemispheres are in a dynamic state of balance, but if one hemisphere becomes more active, attention is biased to the opposite side. Thus, with verbal stimulation, the left hemisphere will be activated and attention will be unconsciously biased to the right ear.

\section{EVIDENCE FROM TELEPHONE EAR PREFERENCE}

In a study of telephone-listening biases, Surwillo (1981) wondered whether there existed a preference for using the right ear. He anticipated that those who use the telephone a great deal would be more likely to show a right ear preference than those who do not. His results revealed no evidence of a right ear preference either at the time the subjectcaller placed the call or in the report of the respondent's usual telephone-listening habit. Indeed, the opposite, i.e. a left ear preference, was found, a preference not attributable to chance. Surwillo's findings suggest that left ear listening was preferred primarily because it was more convenient for right handers to hold the receiver to the left than the right ear while grasping it in the left hand, possibly because this would leave the right hand free for writing, page turning, etc.

By far the most common reason given for listening with the left ear was the need to keep the right hand free for either writing and/or dialling, which would be facilitated by holding the receiver to the left ear with the left hand. However, subjects who listened with the right ear, claimed that it was because they were right handed, and thus they pick up the phone with that hand. Only a small proportion of subjects reported "hearing" or understanding better by holding the receiver to a particular ear.

More instructive is the finding that heavy use of the telephone was associated with a marked preference for the left ear. In other words, the left ear appears to be the ear of 
choice for persons who process a great deal of verbal information via the telephone. Of course, frequent phoners might also need to use the right hand for conversation-related activities.

\section{HANDEDNESS AND EAREDNESS}

Although the writing hand is the most frequently used criterion to determine an individual's handedness (Annett 1973), it is also most apt to be subject to social pressure in childhood. Hence, most investigators resort to preference measurement techniques where hand use is determined by a number of unimanual tasks, such as those listed in Oldfield's (1971) Edinburgh Handedness Inventory.

Since some of the behaviors used to measure ear preference also involve a hand action, such as placing a telephone receiver to one ear or the other, some claim that the side of the preferred ear is determined by the side of the preferred hand (Clark 1957; Fridenberg 1904). Within this context, there does appear to be a relationship between the two types of preference when the earedness measure involves some sort of preferred hand action (Clark 1957) as in placing a telephone receiver on one's ear.

In an experiment on earedness, defined by the authors (Noonan and Axelrod 1981) as the preferential orientation of one ear towards a sound source, or alternatively, the preferential positioning of a sound source so that it stimulates one ear more than the other, ear choice was found to be significantly related to handedness.

There is more to this issue than simply connecting hands to ears. In fact, cognitive psychologists of various training backgrounds have seen in it an interesting puzzle. For example, Oxbury (Oxbury and Gardiner 1967) challenged the hypothesis of a laterality effect in dichotic listening upon which the idea is based. In a similar vein, Inglis (1965) cited evidence suggesting that the right ear effect in dichotic listening experiments could be an artifact of the order of recall, although Bryden's (1967) work would negate this possibility.

\section{EVIDENCE FROM BILINGUALISM STUDIES}

Most work on cerebral lateralization has dealt almost exclusively with speakers of a single language, but more recently, studies like the present one have explored ear preferences and processing efficiency among bilinguals. For instance, of the many factors associated with the language acquisition of bilinguals, the age of onset of bilingualism has provided the least equivocal results in behavioural studies (Genesee 1977). Bilinguals who acquired their second language at infancy appear to employ a different strategy in processing verbal material than that used by bilinguals who acquired their second language later in life. Moreover, bilinguals seem to process meaning more rapidly and more efficiently than monolinguals in the right hemisphere (see Vaid and W. E. Lambert 1979). Furthermore, it would appear that early bilinguals are not only more skilled at making semantic discriminations, but are especially skilled when the input is initially directed to the right hemisphere (Vaid 1984). In a study of interference in tapping rate by concurrent speech production in fluent bilinguals, Sussman, Franklin and Simon (1982) found much greater left-hemisphere dominance for subjects who were bilingual from birth, and greater righthemisphere language processing in subjects who became bilingual later than infancy.

In the case of translators or simultaneous interpreters, Green (1986) proposes a model whereby the output from L2 can be suppressed within the system itself (internal suppression) or by the L1 system externally suppressing the activity of L2 (external suppression). Since translation or interpretation into $\mathrm{L} 1$ requires that the speaker not simply repeat the message in L2, Green proposes that suppression of the output from L2 is achieved internally in the same way as a monolingual speaker might avoid simply repeat- 
ing a word or phrase just heard. In other words, when speaking L1 spontaneously, L2 is externally suppressed, whereas when interpreting from $\mathrm{L} 2$ to $\mathrm{L} 1$, the output of $\mathrm{L} 2$ is internally suppressed.

Following Albert and Obler's (1978) first review of cerebral asymmetries of the linguistic functions of bilinguals and polyglots, Paradis $(1987 ; 1989)$ put forward five possible hypotheses: i) both or additional languages are lateralized to the hemisphere that is specialized for linguistic functions (generally the left); ii) one or more languages are lateralized to the left hemisphere, whereas the others are represented in the right hemisphere; iii) only L1 is lateralized to the left hemisphere, whereas the others are bilaterally represented in both hemispheres, especially when these languages are acquired later on in life; iv) among bilinguals and polyglots, the hemisphere that is not dominant for linguistic functions (generally the right hemisphere) is more involved in the linguistic functions of all languages than is the case among monolinguals; and v) all of the subject's languages are bilaterally represented. Hypotheses of this sort underline the recent research which examines the role of specific biological, psychological and critical linguistic factors which account for the hemispheric specialization for bilinguals and polyglots ( $c f$. Obler, Zatorre, Galloway and Vaid 1982), such as type of bilingualism (Albert and Obler 1978; Vaid 1983; Genesee 1987); age of acquisition (Genesee 1987); patterns of second language acquisition processing (Vaid 1983); stages of language acquisition (Code 1987); specific language features (Sasanuma, Itoh, Kobayashi and Mori, 1980; Vaid 1983); and finally sex (McGlone 1980; Fabbro 1989) to name but a few. For a more complete breakdown, see Fabbro and Gran (in press).

\section{EVIDENCE FROM SIMULTANEOUS INTERPRETATION}

Only a handful of studies have examined the headphone habits of simultaneous interpreters. For example, in attempts to explain the proclivity of those conference interpreters who sometimes interpret with one headphone slightly off of one ear, some claim that the headset feels too tight; other say that slightly releasing one of the ears in this fashion enables them to monitor their output for both content and volume.

Lawson (1967) made a brief reference to the use of one ear versus the other among interpreters, but the main concern of her paper was selective attention to discourse, in other words, the ability to attend selectively to some aspects of verbal input while rejecting others, rather than the laterality of the more proficient ear. In a description of the tasks, procedures, and environment of simultaneous interpreters, Parsons (1975) queried subjects' use of headphones: four (out of five) said they normally kept an earphone off one ear, either completely or partially. Two claimed it was the right ear, one specified the left ear, one reported alternating, and one failed to reply.

A pilot study (Kraushaar and Lambert 1987) compared simultaneous interpreters' listening ability in their first and second languages when "shadowing" verbal stimuli presented in either one ear or the other. Shadowing is an externally paced, auditory tracking task which involves the immediate vocalization of auditorily presented stimuli, that is, a wordfor-word repetition, or parroting, in the same language, of a message presented through headphones. If we assume that an interpreter removes one headphone from one ear while interpreting, for whatever reason, the question arises as to whether the same ear is consistenly released. Consistent releasing of one ear as opposed to the other could shed light on the cognitive processes involved during both shadowing and simultaneous interpretation. Other variables such as handedness, telephone habits, language used for shadowing exercises (L1 as opposed to L2), as well as language direction during simultaneous interpretation (i.e. from $\mathrm{L} 2$ to $\mathrm{L} 1$ or vice versa) very likely all play separate and combined roles in efficient processing. All these factors were considered in the pilot study. 
Results indicated that for $\mathrm{L} 2$ input information, the ear of reception did not influence the number of errors committed while shadowing, whereas in L1, there was a tendency to commit fewer errors when L1 was processed through the right ear-left hemisphere route, a fact we felt warranted further study.

Numerous studies carried out at the School for Translators and Interpreters at the University of Trieste in Italy have also looked into the neurolinguistic and neuropsychological aspects of simultaneous interpretation. Spiller-Bosatra, Daro, Fabbro \& Bosatra (1990) found that 3rd year students made significantly more errors than 4th year students when shadowing words presented to the left ear, as opposed to the right. In other experiments (Gran and Fabbro 1989 and Fabbro, Gran and Gran 1990), hemispheric specialization for semantic and syntactic language components in L1 and L2 were studied by presenting 60 sentences in one language to one ear only, and at the same time, by sending the translation of these sentences to the other ear. Some sentences were correct, others contained semantic errors and others, syntactic errors. Results indicated that student interpreters did not show any significant difference between ears in recognizing correct sentences, whereas the professional interpreters recognized significantly more sentences with semantic mistakes in L1 when listening with their right ear, and significantly more sentences with semantic mistakes in L2 when listening with their left ear. The professional interpreters also recognized significantly more sentences with syntactic mistakes in Ll when listening with their left ear and in L2 when listening with their right ear. The authors concluded that professional interpreters adopt semantic strategies (meaning-based translation), whereas beginner interpreters appear to adopt a more syntactic and word-forword approach to interpretation.

Recent studies comparing shadowers and interpreters (Green, Schweda-Nicholson, Vaid and White 1989) revealed greater manual tapping interference when interpreting than when shadowing, suggesting that these tasks differ in their processing demands and in their pattern of hemispheric involvement. Shadowing was specialized in the left hemisphere while simultaneous interpretation was processed bilaterally, which reflected a possible difference in the level of processing in that shadowing involves phonemic level processing, whereas simultaneous interpretation involves semantic processing.

Since processing incoming stimuli through one ear vs. the other appears to influence performance for a relatively shallow task such as shadowing (Kraushaar and Lambert 1987), one wonders what the results would be following deeper and more semantically meaningful tasks such as simultaneous interpretation, especially when interpreting entire speeches as opposed to isolated words or even unrelated sentences. Furthermore, if the performance of a simultaneous interpreter is significantly affected by the ear of reception, a more comprehensive study of this variable might help not only to better understand the fascinating process of interpretation but also how one might modify certain interpretertraining techniques (as well as headphone design), in order to improve upon interpretation efficiency itself. This line of thought led to the present study.

\section{Method}

Two speeches, one in English and the other in French, were recorded stereophonically by native speakers at a rate of approximately 108 words per minute. Both speeches had been delivered by Canadian Prime Ministers, greeting foreign Heads-of-State visiting Canada, and were taken verbatim from Hansards $(1984 ; 1986)$. Each speech lasted approximately 12 minutes and made no demands on subjects' knowledge of specialized or technical vocabularies. 
Subjects

Of the 21 subjects tested, 13 were professional interpreters and 8 were interpretation students enrolled in the final year of a two-year Diploma Programme in Interpretation at the University of Ottawa. All students had interpreted for at least six months before serving as subjects. Of the 21 subjects, 18 were right handed and 3, left handed. Subjects' handedness was determined by the Lambert and Lambert Questionnaire (1985), based, in turn, on the Edinburgh Handedness Inventory (Oldfield 1971). Only the results of the right-handed subjects were analyzed.

The breakdown of subjects according to sex and language was as follows: 6 female francophones; 4 female anglophones; 2 male francophones; 6 male anglophones. In other words, 8 subjects claimed French as their native or dominant language, and 10 English.

\section{Procedure}

Both speeches were recorded professionally at the Secretary of State's Interpretation Division in Hull, Quebec, to ensure quality of sound and to calibrate stereophonic effect. Subjects were provided with Sennheiser stereophonic headphones for interpreting. Two Panasonic tape-recorders (Model No. RQ-495) were used, one to record subjects' interpretation, and the other to relay speeches to subjects' left ear, right ear, and both ears, by way of a special custom-made device (Capello Audio of Ottawa), which included a dial enabling the experimenter to shunt the message to one ear or the other, and an amplifier which was connected to the source tape-recorder, enabling subjects to regulate volume to a comfortable level. This deserves some explanation: in a pilot-test, subjects complained that when the message was shunted to their non-preferred ear, they could not hear properly and the sound was too faint. It was felt that giving subjects the means to control the volume would eliminate the problem. However, this being an incidental learning paradigm, subjects were not informed of the nature of the experiment beforehand, other than the fact that they would be required to interpret various passages. To this effect, the device used to send the message to either ear was hidden from the subjects during the experiment. It was only after the experiment that subjects were informed of the nature of the experiment and that a questionnaire was administered to determine handedness, bilinguality, telephone habits, and whether or not subjects had any hearing impairment.

Subjects only interpreted in a direction determined by their mother-tongue: Anglophone subjects interpreted the French text into English and Francophone subjects, from English towards French. Each twelve-minute long speech was carefully divided into four three-minute segments. The first segment was used as a warm-up and therefore never evaluated. Following the warm-up, and without any interruption, the experimenter channelled the next segment of speech to one of three possible directions:
Condition I
Both ears
(Segment $A=3$ minutes)
Condition II
Left ear only
(Segment $B=3$ minutes)
Condition III
Right ear only
(Segment $\mathrm{C}=3$ minutes)

To eliminate the possibility of an order-effect, all possible order combinations were used: $\mathrm{ABC}, \mathrm{ACB}, \mathrm{CBA}$, etc., totaling 6 possibilities. The sequence was repeated with 3 sets of subjects, requiring a total of 18 subjects.

To facilitate correction of output, all subjects' interpretations were transcribed and the transcriptions were matched against the original by two judges working independently. Interjudge correlation across 18 subjects for the coding of errors was .91 ; both judges were left blind to the subjects' conditions and to the purposes of the experiment.

Scoring of interpretation protocols was based on the study of Henri C. Barik (1975). Briefly, an interpreter's version may depart from the original version in three ways: the 
interpreter may omit some material from the original version, add some material, or substitute material, which, if at considerable variance with the original, may constitute a meaning error. Furthermore, penalties were weighted differently depending on whether they affected a word, phrase, or sentence. The following scoring table serves to illustrate the scoring procedure followed by both judges:

\section{Scoring Scale for Penalty Points}
Type of error
1. Omission
2. Addition
3. Meaning Error

\begin{tabular}{lll}
\multicolumn{3}{l}{ Weights for extent of error } \\
Word & Phrase & Sentence \\
0.5 & 2 & 3 \\
0.5 & 1 & 2 \\
1 & 3 & 5
\end{tabular}

A more detailed description of the procedure followed to arrive at such a categorization can be found elsewhere (Barik 1971; Kraushaar and Lambert 1987).

\section{Results}

Since this is a pilot study of a new research domain and since the number of subjects is so limited, the following results should be considered mainly as suggestive trends for future research. The main subject information is summarized in Tables 1 and 2.

1) In terms of interpretation proficiency, the binaural input condition is apparently not the most advantageous input alternative since only 4 of the 18 subjects performed best under that condition. Instead, one form or another of monaural input is more advantageous: when the binaural input condition is compared with the better monaural input condition, be it left or right, the monaural alternative promotes the most proficient interpretation score for 14 of the 18 subjects $\left(\mathrm{X}^{2}=5.56, \mathrm{df}=1, \mathrm{p}<.02\right)$. The implication of this finding is that two ears are not better for message reception when interpreting. Rather, one ear is a better alternative, and for some this would be the right ear, and for others, the left ear.

Moreover, when the total error scores (see Table 2) are considered, the monaural input condition produces fewer errors than the binaural condition: mean errors 42.36 for the better-ear monaural vs. 48.19 for the binaural $(\mathrm{t}=2.33, \mathrm{df}=17, \mathrm{p}<.03)$, with a 2 - tailed significance test). 
TABLE 1

Summary of Interpreter Characteristics: Right-handed Subjects Only

\begin{tabular}{|c|c|c|c|c|c|c|c|c|}
\hline & \multirow{3}{*}{ Sex } & \multirow{3}{*}{ Status ${ }^{\mathbf{a}}$} & \multirow{2}{*}{\multicolumn{3}{|c|}{$\begin{array}{l}\text { Preferred Ear when: } \\
\text { Interpreting / Telephoning }\end{array}$}} & \multicolumn{3}{|c|}{ Total Interpretation Errors ${ }^{b}$} \\
\hline & & & & & & Binaural & Left Ear & Right Ear \\
\hline & & & $\begin{array}{l}\text { Normal } \\
\text { Routine }\end{array}$ & $\begin{array}{l}\text { Unde } \\
\text { Stress }\end{array}$ & & & & \\
\hline $\mathbf{S 1}$ & M & $\mathrm{P}$ & Both & $\mathrm{R}$ & $\mathrm{R}$ & 53.5 & $\underline{32.5}$ & 52.5 \\
\hline$\$ 2$ & M & $\mathrm{P}$ & Both & Both & $\mathrm{L}$ & 21.5 & 9.0 & 19.5 \\
\hline$\$ 3$ & $\mathrm{~F}$ & $\mathrm{P}$ & Both & $\mathrm{L}$ & $\mathrm{L}$ & 7.5 & $\overline{21.5}$ & 31.5 \\
\hline$\$ 4$ & $\mathbf{M}$ & $\mathbf{S}$ & Both & $\mathbf{L}$ & $\mathrm{L}$ & $\overline{23.0}$ & $\underline{18.0}$ & 23.5 \\
\hline S.5 & $\mathrm{F}$ & $\mathbf{S}$ & Both & $\mathbf{L}$ & $\mathrm{L}$ & 64.0 & $\underline{53.0}$ & 56.0 \\
\hline S6 6 & M & $S$ & Both & $\mathbf{L}$ & $\mathrm{L}$ & 43.5 & 29.0 & 57.0 \\
\hline S7 & $\mathrm{M}$ & $S$ & Both & $\mathbf{R}$ & $\mathrm{L}$ & 42.0 & $\overline{54.0}$ & $\underline{36.0}$ \\
\hline S8 & $\mathrm{F}$ & $S$ & Both & $\mathbf{L}$ & $\mathbf{R}$ & 63.5 & 60.0 & 63.5 \\
\hline S9 & $\mathbf{M}$ & $S$ & Both & $\mathrm{L}$ & $\mathrm{L}$ & 73.5 & 98.0 & $\underline{70.0}$ \\
\hline S 10 & $\mathbf{M}$ & $\mathbf{P}$ & Both & Both & $\mathrm{L}$ & $\underline{41.5}$ & 61.5 & 48.5 \\
\hline S11 & $F$ & $\mathbf{P}$ & $\mathrm{L}$ & $\mathrm{L}$ & $\mathbf{L}$ & 49.5 & 61.5 & 69.5 \\
\hline $\mathrm{S} 12$ & $\mathrm{~F}$ & $\mathbf{P}$ & $\mathbf{R}$ & $\mathrm{R}$ & $\mathbf{L}$ & $\overline{66.0}$ & $\underline{50.0}$ & 77.0 \\
\hline S13 & $\mathrm{F}$ & $\mathbf{P}$ & $\mathrm{L}$ & $L$ & $\mathbf{L}$ & 42.0 & 39.0 & 32.5 \\
\hline S14 & $\mathrm{F}$ & $P$ & Both & $\mathrm{L}$ & $\mathrm{L}$ & 85.0 & $\underline{66.5}$ & 67.0 \\
\hline S15 & $F$ & $S$ & Both & Both & $\mathrm{R}$ & 76.0 & $\overline{65.5}$ & 78.0 \\
\hline S16 & $\mathrm{F}$ & $S$ & Both & Both & $\mathrm{L}$ & 68.5 & 62.5 & 77.5 \\
\hline S17 & $\mathrm{F}$ & $\mathrm{P}$ & $\mathbf{R}$ & Both & $\mathrm{L}$ & 31.5 & $\underline{19.0}$ & 36.0 \\
\hline S18 & $\mathbf{M}$ & $\mathrm{P}$ & Both & Both & - & $\underline{15.5}$ & $\overline{27.5}$ & 28.5 \\
\hline
\end{tabular}

$\overline{\mathrm{a}} \mathrm{P}=$ professional interpreters; $\mathrm{S}=$ advanced students.

b "Best" input condition (i.e., with least errors) is underlined. Chi square tests of various input conditions: Monaural (better ear) $(n=14)$ vs. Binaural $(n=4), X^{2}=5.56, d f=1, p<.02$; Left ear $(n=11)$ vs. Right ear $(n=3)$, $\mathrm{X}^{2}=3.26, \mathrm{df}=1$, not significant $(3.84$ needed at .05 level).

c Under stress conditions (e.g. speaker is not clear or loud enough), the ear left covered, i.e. the ear not released. For all subjects, these conditions prevail for about $5 \%$ to $10 \%$ of the time.

Table 2

Error Typea Counts: Binaural vs. Better-Ear Monaural

\begin{tabular}{|c|c|c|c|c|c|}
\hline \multirow[b]{2}{*}{ Error Type } & \multicolumn{2}{|c|}{ Mean Weighted Error Scores } & \multirow[b]{2}{*}{ t-test $t^{b}$} & \multirow[b]{2}{*}{ df } & \multirow{2}{*}{$\begin{array}{l}\text { 2-tailed } \\
\text { Probabilities }\end{array}$} \\
\hline & Monaural & Binaural & & & \\
\hline Omission & 19.17 & 23.33 & 2.11 & 17 & $.05^{*}$ \\
\hline Addition & 2.28 & 2.83 & 1.03 & 17 & .32 \\
\hline Semantic & 13.17 & 13.22 & 0.03 & 17 & .98 \\
\hline Phrasing & .78 & 4.56 & 0.56 & 17 & .58 \\
\hline Gieneral & 4.58 & 4.25 & -0.60 & 17 & .56 \\
\hline Total (all types) & 42.36 & 48.19 & 2.33 & 17 & $.03 *$ \\
\hline
\end{tabular}

$\vec{a}$ Description of error types and the weighting system employed can be found in Barik (1975) and Kraushaar and Lambert (1987).

b Significance tests based on repeated measures t-tests; asterisk (*) indicates statistical significance beyond the .05 percent confidence level, two-tailed test. 
2) Considering the 14 subjects who perform best with a monaural input, 11 of the 14 perform more accurately with the left ear than with the right ear $\left(X^{2}=4.57, \mathrm{df}=1\right.$, $\mathrm{p}<.05$ ), suggesting not only a monaural advantage, but also a left ear advantage (LEA). The data, however, are not substantial enough to support a logical extension of such an advantage, i.e., the comparison of the left ear input over the binaural: 11 subjects perform best with the left ear input $\left(X^{2}=3.26\right.$, d.f. $\left.=1, p<.05\right) ; 3.84$ is needed at the .05 level of confidence.

Furthermore, when the total error scores are considered, and the left ear and right ear input conditions are compared, the left ear has fewer errors on the average (mean scores 46.00 for left ear, 51.33 for right ear), but the error differences are not statistically reliable ( $\mathrm{t}=1.53, \mathrm{df}=17, \mathrm{p}<.14$, with a two-tailed significance test). At best, therefore, the evidence for a LEA for interpreting is not robust; increasing the size of the subject pool will throw light on this important point. Although marginal in the statistical sense, the trend indicated is interesting and suggestive.

3) There is little evidence to suggest that interpreters normally disengage one ear while interpreting. When questioned, 14 out of 18 subjects indicated that their routine is to leave both ears engaged for at least $80 \%$ of their working time. Most claimed that both headphones placed squarely on both ears blocks out any noise such as that made by the other interpreter sharing the same booth. Under "stressful" or unusual conditions, however, 12 subjects said that they might temporarily release one ear but only for $10 \%$ of the time or less. "Stressful" conditions for interpreters range from having to interpret speeches at 200 words per minute, interpreting speakers with foreign accents, interpreting from $\mathrm{L} 1$ into L2, interpreting technical material, interpreting material that is being read, etc.

These findings are not supportive of Parsons' (1975) study where large proportions of interpreters stated that they disengage one ear for various reasons. Instead, most of our subjects indicated that binaural input was maintained as the normal procedure. This would suggest that interpreters can adequately hear their own productions in language $\mathrm{A}$ behind two earphones and they apparently are also able to monitor the intensity of that output.

4) The relations of ear preference for telephoning to both ear preference for interpreting and to interpretation accuracy were both examined. Significantly more subjects preferred the left ear over the right ear for telephoning (14 out of $18 ; \mathrm{X}^{2}=5.56, \mathrm{df}=1$, $\mathrm{p}<.02$ ) which is in line with Surwillo's (1981) finding that the left ear is strongly favored in telephoning by those who are heavily involved in verbal communications.

Routinized ear preferences for telephoning might be expected to be reflected in a similar ear preference for interpreting, but this is not the case with this sample of subjects: few favor the left ear for interpreting. Such findings suggest that these subjects think of the interpretation process as fundamentally different from telephone conversations.

Furthermore, there is no congruence between proclaimed preferred ear for interpretation (where left, right or both are all options) and relative proficiency under the corresponding input condition: only 8 out of 18 show such a correspondence while 10 do not. Nor is there any correspondence between telephone ear preference and proficiency in interpreting under the corresponding ear input condition: 9 show correspondence while 9 do not. Thus, ear of preference for telephoning or for interpreting has no systematic relation to actual accuracy in interpreting. Neither the telephone habit nor the habitual use of binaural earphones when interpreting are related to actual proficiency in interpreting. Actually, most of our subjects have listening habits that direct them away from the most advantageous monaural, left-ear input alternative. 
5) Attention was given to the types of errors made in the compilation of overall errors during interpretation. In Table 2, these error types are compared for the binaural input condition vs. the better-ear monaural condition. The finding of interest is that significantly more omissions occur under binaural than under monaural conditions (mean scores are 23.33 for binaural and 19.17 for monaural, $t=2.11$, df $=17, p<.05$ ). None of the other forms of interpretation errors appear to be affected. More omission errors occur under right-ear input (26.89) than under left-ear (21.56), but again this difference does not quite reach statistical significance $(t=1.80$, $\mathrm{df}=17, \mathrm{p}<.09)$. In brief, then, the advantage of the monaural input condition and of the left-ear condition in particular, appears to be a matter of memory and holding capacity of input message details. Binaural input seems to hamper this memory / holding capacity.

We can compare these results with those obtained for shadowing (Kraushaar and Lambert 1987): when shadowing in one's L2, the ear of reception did not appear to matter, be it one ear or both ears, whereas when shadowing in one's L1, the input speech was better processed when directed through the right-ear-to-left-hemisphere route. The results of the present experiment indicate that when interpreting simultaneously from $\mathrm{L} 2$ to $\mathrm{L} 1$, right handed interpreters function more efficiently with a left ear input, and that processing incoming messages through one ear is more effective than through two. This contrast between shadowing and interpreting would be worth exploring in future research.

Very few studies have examined the relation between ear preference, as present in one-eared situations, and ear proficiency, as defined by auditory processing asymmetries (Bilto and Peterson 1944; Porac and Coren 1981: 29). Porac and Coren found only a 54\% concordance between the preferred ear as determined by means of a questionnaire and the more accurate ear as measured by threshold sensitivity, a value not significantly different from chance. However, the preferred ear did appear to extract slightly more information than the nonpreferred ear during dichotic listening. Porac and Coren found a $57 \%$ concorclance between the side of one-ear preference and the side of dichotic preference, albeit not significant.

\section{Discussion}

The discovery of no right ear advantage for processing verbal information is difficult to reconcile with the dichotic listening literature which clearly indicates that, for right handed individuals, the right ear would be more efficient than the left whenever verbal information is to be processed. So how do we explain the fact that interpreters do not perform significantly better when they interpret via the right ear? Whatever is involved, interpreters are apparently not aware of ear differences in efficiency. When asked which ear they usually released when interpreting, very few showed a concordance between the preferred ear as indicated by the ear they did not release and the accurate ear as deterrnined by the accuracy scores for interpretation. Put another way, interpreters are apparently unaware of the fact that their performance while interpreting might be enhanced by a. specific ear of input. We also must try to explain the main findings, that interpreters perform significantly better with monaural input, and that the left ear input route is an advantageous alternate.

One possible explanation lies in the nature of the two tasks involved during simultaneous interpretation. From a cognitive point of view, interpreters are basically involved in two concurrent activities: listening and speaking, i.e. decoding and encoding. Both activities are verbal and hence one would expect a favoring of the right-ear-to-left-hemisphere system for both tasks. The results of the present experiment suggest that interpreters unconsciously arrive at a potentially valuable means of solving the dual-task dilemma, and that the solution is facilitated by a monaural input and hampered by a bin- 
aural one. Interpreters appear to listen to, hold in memory, and start the language switch process of the incoming message, arriving in language $B$, by using the left-ear-to-righthemisphere route, whereas they use the right-ear-to-left hemisphere route to monitor and polish their output into language A.

Figure 1 attempts to diagram this hypothesized solution. Note that if only one ear is engaged in the decoding process, as happens when the other ear's earphone is disengaged, then the unengaged ear would be free to attend to encoding processes with a minimum of interference. If the left ear route is used for decoding plus translating, then the right ear route and the left hemisphere are left relatively free for the critical task of perfecting a professional interpretation into language $\mathrm{A}$.

These results and the explanation offered above direct attention to the needed research on the direction of interpretation: $\mathrm{L} 2$ to $\mathrm{L} 1, \mathrm{~L} 1$ to $\mathrm{L} 2$, or both ways. Interpreters in most Western nations are expected to interpret from L2 to L1. Canada is an exception, since interpreters in this country are trained and expected to interpret in both directions, i.e. French into English and English into French. The Soviet Union is also an exception since interpreters typically interpret only from $\mathrm{L} 1$ to $\mathrm{L} 2$. Two reasons are often cited for this preference: one, for reasons of political security, Soviets prefer to use their own Russian-speaking interpreters. The second reason, however, is more relevant to the present study: Soviet authorities feel more secure knowing that the interpreter has fully grasped the incoming message in $\mathrm{Ll}$ even though the interpreter's output may be accented or non-native speech in L2, as would be the case if a Soviet interpreter interpreted a Russian message into English, for example. Apparently, Western audiences would rather hear a fluent, native-like interpretation in L1, even though the interpreter may not always grasp $100 \%$ of the incoming message in L2. One wonders what would happen if interpreters from non-Eastern bloc nations were to interpret in the opposite direction, i.e. from $\mathrm{L} 1$ to $\mathrm{L} 2$. Would the left-ear route be used to process the incoming message through headphones, and would the right-ear route be used to allow the interpreter to monitor his / her own output? It would be worth testing this possibility since Sussman et al. (1982) found that within bilingual populations, there existed significant differences in the relative degree of language lateralization when L1 compared to L2 is being used.

This L1 vs. L2 difference has been examined in a preliminary manner by Kraushaar and S. Lambert (1987) for shadowers. Results indicated that when shadowing in L2, the ear of reception did not appear to influence the number of errors committed, whereas when shadowing in L1, fewer errors were committed through the right ear route. The fact that such a difference might exist for L1 input, but not for L2 input poses interesting questions about those who are expected to interpret in two directions, in other words interpreters having two working languages, those categorized as "double As".

Another possible explanation of our major findings is that bilingual subjects are able to make greater use of their right hemispheres when processing verbal information than are unilinguals. Most work on cerebral lateralization has dealt almost exclusively with speakers of a single language. A study by Vaid and W.E. Lambert (1979) raised the issue of lateralization among bilinguals based on the notion that bilingualism itself, which represents a distinctive form of language experience, may have an important influence on hemispheric specialization. The Sussman et al. (1982) study of interference in manual tapping rate from concurrent speech production indicated that for bilinguals, the relative language laterality performances were weaker (less left-hemisphere lateralized) than for monolinguals, and that bilinguals, as a group, demonstrated more symmetric hemispheric language laterality.

Of the many factors found to affect the language acquisition histories of bilinguals, the age of onset of bilingualism has provided the least equivocal results in behavioural 
studies (Genesee, Hamers, Lambert, Mononen, Seitz and Starck 1978). In that study, bilinguals who acquired their second language at infancy appear to employ a different strategy in processing verbal material than that used by bilinguals who acquired their language later in life. Those who became bilingual at infancy or in early childhood appear to use an analytic, semantic approach to verbal material - more a left hemisphere approach - while those who acquired their second language during adolescence or thereafter tended to rely more on extralinguistic (e.g. physical) features of the linguistic stimuli - more a. right hemisphere approach. Vaid (1984) examined the performance of early and late French-English bilinguals and monolingual controls on speeded word-pair comparisons and found that early bilinguals were not only more skilled at making semantic discriminations, but that they were especially skilled when the input was initially directed to the right hemisphere. Thus, it could be that simultaneous interpreters, as bilinguals, employ different strategies in processing verbal material, including a greater utilization of right hemisphere functions.

In conclusion, this paper presents both theoretical and practical suggestions about the ear-brain relations which stem from an empirical study which indicated that the processing of verbal information by simultaneous interpreters is more efficient when the nessages to be interpreted are directed to one ear rather than to both ears. Furthermore, for right handed interpreters, the more efficient ear appears to be the left, as measured by performance accuracy. These results suggest a possible model for how interpreters cope with the double-task demands of simultaneous interpretation. The model might also help explain how humans in general handle two or more ongoing tasks.

\section{REFERENCES}

ALBERT, M. L. and L. K. OBLER (1978): The Bilngual Brain. Neuropsychological and Neurolinguistic Aspects of Bilingualism, Academic Press, New York.

ANNETT, M. (1973): "Handedness in Families", Annals of Human Genetics, 37, pp. 93-105.

B.ARIK, H. C. (1971): "A Description of Various Types of Omissions, Additions and Errors of Translation Encountered in Simultaneous Interpretation", Meta, 16, p. 199.

B.ARIK, H. C. (1975): "Simultaneous Interpretation: Qualitative and Linguistic Data", Language and Speech, 18 , pp. 272-297.

B.ARTZ, W. H., SATZ, P. and E. FENNELL (1967): "Grouping Strategies in Dichotic Listening: The Effects of Instructions, Rate, and Ear Asymmetry", Journal of Experimental Psychology, 74, pp. 132-136.

B.ERTELSON, P. (1982): "Lateral Differences in Normal Man and Lateralization of Brain Function", Int. J. Psyhol. 17, pp. 173-210.

B.ILTO, B. S. and G. E. PETERSON (1944) : "The Relation Between Ear Preference and Hearing Acuity", Journal of Speech Disorders, 9, pp. 123-125.

BROADBENT, D. E. (1954): "The Role of Auditory Localization in Attention and Memory Span", Journal of Experimental Psychology, 47, pp. 191-196.

BROADBENT, D. E. and M. GREGORY (1964): "Accuracy of Recognition for Speech Presented to the Right and Left Ears", Quarterly Journal of Experimental Psychology, 16, pp. 359-360.

B.RYDEN, M. P. (1967): "An Evaluation of some Models of Laterality Effects in Dichotic Listening", Acta Otolaryngologica, Stockholm, 63, pp. 595-604.

CARR, B. M. (1969): "Ear Effect Variables and Order of Report in Dichotic Listening", Cortex, 5, pp. 63-68.

CLARK, M. M. (1957): Left Handedness: Laterality Characteristics and their Education Implications, London, University of London Press.

CODE, C. (1987): Language, Aphasia, and the Right Hemisphere. John Wiley and Sons, Chichester.

DIRKS, D. (1964): "Perception of Dichotic and Monaural Verbal Material and Cerebral Dominance for Speech", Acta Oto-laryngologica, Stockholm, 58, pp. 73-80.

FABBRO, F. (1989): "Neurobiological Aspects of Bilingualism and Polyglossia, L. Gran and J. Dodds (Eds.), The Theoretical and Practical Aspects of Teaching Conference Interpretation, Campanotto, Udine, pp. 71-82.

FABBRO, F. and L. GRAN (in press): "Neurological and Neuropsychological Aspects of Polyglossia and Simultaneous Interpretation", S. Lambert (Ed.), Bridging the Gap, Empirical Research on Interpretation.

FABBRO, F., GRAN, B. and L. GRAN (1990): "Hemispheric Specialization for Semantic and Syntactic Components of Languages in Simultaneous Interpreters", Brain and Language. 
FRIDENBERG, P. (1904): "Binocular Single Vision and Hypotheses of the Dominant Eye, Ophthalmology, 1, pp. 196-212.

GEFFEN, G. and K. QUINN (1984): "Hemispheric Specialization and Ear Advantages in Processing Speech", Psychological Bulletin, 96, 2, pp. 273-291.

GENESEE, F. (1977): "Summary and Discussion", P. A. Hornby (Ed.), Bilingualism: Psychological, Social and Educational Implications, New York, Academic Press, pp. 147-164.

GENESEE, F. (1987): "Neuropsychology and Second Language Acquisition", L. M. Beebe (Ed.), Issues in Second Language Acquisition, Harper \& Row, New York, pp. 82-112.

GENESEE, F., HAMERS, J., LAMBERT, W. E., MONONEN, L., SEITZ. and R. STARK (1978): "Language Processing in Bilinguals", Brain and Language, 5, pp. 1-12.

GRAN, L. and L. FABBRO (1989): "Cerebral Lateralization for Syntactic and Semantic Components in L1 (Italian) and L2 (English) in Interpreting Students: Training Implications for Simultaneous Interpretation", D. Lindberg Hammond (Ed.) Coming of Age: American Translators Association Conference 1989, Learned Information Inc., Medford, N.J. pp. 133-142.

GREEN, A., SCHWEDA-NICHOLSON, N., VAID, J., WHITE, N. and R. STEINER (1990): "Hemispheric Involvement in Shadowing vs. Interpretation: A Time-sharing Study of Simultaneous Interpreters with Matched Bilingual Controls, Brain and Language, 39, pp. 107-133.

GREEN, D. W. (1986): "Control, Activation, and Resource: A Framework and a Model for the Control of Speech in Bilinguals", Brain and language, 27, pp. 210-223.

Hansard $(1984 ;$ 1986): House of Commons Debates Official report (Hansard), Vol. 128, n_ 204, First Session, 33rd Parliament, Tuesday, May 8, 1984 and January 13, 1986. Speeches welcoming Prime Minister Nakasone (Japan) and President Miguel de la Madrid Hurtado (Mexico).

INGLIS, J. (1965): "Dichotic Listening and Cerebral Dominance", Acta Oto-laryngologica, Stockholm, 60 , pp. 231-238.

KIMURA, D. (1961a): "Some Effects of the Temporal-lobe Damage on Auditory Perception", Canadian Journal of Psychology, 15, pp. 156-165.

KIMURA, D. (1961b): "Cerebral Dominance and the Perception of Verbal Stimuli", Canadian Journal of Psychology, 15, pp. 166-171.

KIMURA, D. (1967): "Functional Asymmetry of the Brain in Dichotic Listening", Cortex, 3, pp. 163-178.

KINSBOURNE, M. (1975a): "The Mechanisms of Hemispheric Control of the Lateral Gradient of Attention", P. M. Rabbitt and S. Dornic (Eds.), Attention and performance V, pp. 87-97. London, Academic Press.

KINSBOURNE, M. (1975b): "The Ontogeny of Cerebral Dominance", Annals of the New York Academy of Sciences, 263, pp. 244-250.

KRAUSHAAR, B . and S. M. LAMBERT (1987): "Shadowing Proficiency According to Ear of Input and Type of Bilinguality", Canadian Association of Applied Linguistics, 9, 1, pp. 17-31.

LAMBERT, S. M. and W. E. LAMBERT (1985): "Physiology: A Questionnaire", Meta, 30-1, pp. 68-72.

LAWSON, E. A. (1967): "Attention and Simultaneous Translation", Language and Speech, 10, pp. 29-35.

McGLONE, J. (1980): "Sex Differences in Human Brain Organization: A Critical Survey", The Behavioral and Brain Sciences, 3, pp. 215-227.

MORAIS, J. (1978): "Spatial Constraints on Attention to Speech", Attention and Performance VII, J. Requin (Ed), pp. 245-260, Lawrence Erlbaum, New Jersey.

NOONAN, M. and S. AXELROD (1981): "Earedness (Ear Choice in Monaural Tasks): Its Measurement and Relationship to Other Lateral Preferences", Journal of Auditory Research, 21, pp. 263-277.

OBLER, L. K., ZATORRE, R. J., GALLOWAY, L. and J. VAID (1982): "Cerebral Lateralization in Bilinguals: Methodological Issues", Brain and Language, 15, pp. 40-45.

OLDFIELD, R. C. (1971): "The Assessment and Analysis of Handedness: The Edinburgh Inventory", Neuropsychologia, 9 , pp. 97-113

OXBURY, S., OXBURY, J. and J. GARDINER (1967): "Laterality Effects in Dichotic Listening", Nature, 214, pp. 742-743.

PARADIS, M. (1987): The Assessment of Bilingual Aphasia, Lawrence Erlbaum Associates Publishers, Hillsdale, N.J.

PARADIS, M. (1989): "Bilingual and Polyglot Aphasia", F. Boller and J. Grafman (Eds.), Handbook of Neuropsychology, vol. 2., Elsevier, Amsterdam, pp. 117-140.

PARSONS, H. M. (1975): "Human Factors Approach to Simultaneous Interpretation", Language, Interpretation and Communication, D. Gerver and H. W. Sinaiko (Eds.), Plenum Press.

PIERSON, J. M., BRADSHAW, J. L., and N. C. NETTLETON (1983): "Head and Body Space to Left and Right, Front and Rear -I. Unidirectional Competitive Auditory Stimulation", Neuropsychologia, 21, pp. 463-473.

PORAC, C. and S. COREN (1981): Lateral Preferences and Human Behaviour, Springer-Verlag, New York.

SASANUMA, S., ITOH, M., KOBAYASHI, Y. and K. MORI (1980); "The Nature of the Task-stimulus Interaction in the Tachistoscopic Recognition of Kana and Kanji Words", Brain and Language, 9, pp. 298-306. 
SATZ, P. (1968): "Laterality Effects in Dichotic Listening", Nature, 218, pp. 277-278.

SATZ, P., LEVY, C. M. and M. TYSON (1970): "Effects of Temporal Delays on the Ear Asymmetry in Dichotic Listening", Journal of Experimental Psychology, 84, pp. 372-374.

SPILLER-BOSATRA, E., DARO, V., FABBRO, F. and A. BOSATRA (1980): "Cerebral Lateralization for Languages and Learning of Simultaneous Interpreting", Suppl. $n^{\circ}$ 2, European Journal of Neluroscience, 11.31 , p. 30 .

SURWILLO, W. (1981): “Ear Asymmetry in Telephone-listening Behavior”, Cortex, 17, pp. 625-632.

SUSSMAN, H., FRANKLIN, P., and T. SIMON (1982): "Bilingual Speech: Bilateral Control?", Brain and Language, 15 , pp. 125-142.

VAID, J. (1983): "Bilingualism and Brain Lateralization", Language Functions and Brain Organization, S. J. Segalowitz (Ed.), New York, Academic Press.

VAID, J. (1984): "Visual, Phonetic and Semantic Processing in Early and Late Bilinguals", M. Paradis and V. Lebrun (Eds.), Early Bilingualism and Child Development, pp. 174-191. Lisse, Swets, and Zeitlinger.

VAID, J. and W. E. LAMBERT (1979): "Differential Cerebral Involvement in the Cognitive Functions of Bilinguals", Brain and Language, 8, pp. 92-110.

Favored route for input message processing: uses left-ear-to-right hemisphere.

It also leaves left hemisphere free-er from input processing.

Thus, interpreter can capitalize on less active left hemisphere to involve it with own speech output.

I. this internal separation of functions, the dual task is facilitated by the distinct ear-tohemisphere differences.
Less advantaged input message processing route; if not used, it leaves left hemisphere less occupied for input analysis and more free to analyze or process own verbal output.

Figure 1

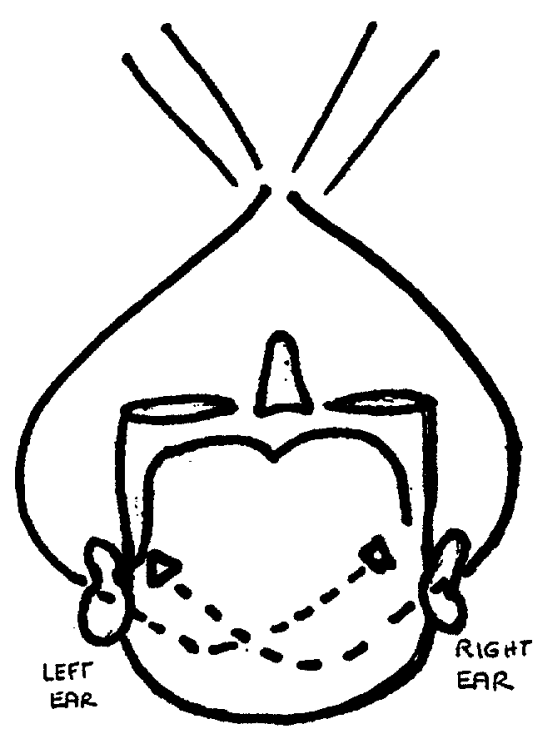

